\title{
Clinical characteristics of chronic idiopathic intestinal pseudo-obstruction in adults
}

\author{
S D Mann, H S Debinski, M A Kamm
}

\begin{abstract}
Background-Chronic idiopathic intestinal pseudo-obstruction, a syndrome of ineffectual motility due to a primary disorder of enteric nerve or muscle, is rare.

Aims-To determine the clinical spectrum, underlying pathologies, response to treatments, and prognosis in a consecutive unselected group of patients.

Methods-Cross sectional study of all patients with clinical and radiological features of intestinal obstruction in the absence of organic obstruction, associated with dilated small intestine (with or without dilated large intestine), being actively managed in one tertiary referral centre at one time.
\end{abstract}

Results-Twenty patients (11 men and nine women, median age 43 years, range 22-67) fulfilled the diganostic criteria. Median age at onset of symptoms was 17 years (range two weeks to 59 years). Two patients had an autosomally dominant inherited visceral myopathy. Major presenting symptoms were pain $(80 \%)$, vomiting $(75 \%)$, constipation $(40 \%)$, and diarrhoea $(20 \%)$. Eighteen patients required abdominal surgery, and a further patient had a full thickness rectal biopsy. The mean time interval from symptom onset to first operation was 5.8 years. Histology showed visceral myopathy in 13, visceral neuropathy in three, and was indeterminate in three. In the one other patient small bowel motility studies were suggestive of neuropathy. Two patients died within two years of symptom onset, one from generalised thrombosis and the other from an inflammatory myopathy. Of the remaining 18 patients, eight were nutritionally independent of supplements, two had gastrostomy or jejunostomy feeds, and eight were receiving home parenteral nutrition. Five patients were opiate dependent, only one patient had benefited from prokinetic drug therapy, and five patients required formal psychological intervention and support.

Conclusions-In a referral setting visceral myopathy is the most common diagnosis in this heterogeneous syndrome, the course of the illness is usually prolonged, and prokinetic drug therapies are not usually helpful. Ongoing management problems include pain relief and nutritional support.

(Gut 1997; 41: 675-681)
Keywords: adult; intestinal; pseudo-obstruction; myopathy; neuropathy

Patients with chronic idiopathic intestinal pseudo-obstruction (CIIP) have a variety of underlying pathologies which result in defective gut motility. The primary feature is clinical and radiological evidence of intestinal obstruction in the absence of a mechanical lesion. The condition was first recognised by Dudley et al in 1958 who described 13 patients with clinical features of bowel obstruction in the absence of a mechanical cause in whom recurring symptoms of pain, vomiting, and distension led to multiple laparotomies. ${ }^{1}$ The term "chronic idiopathic intestinal pseudo-obstruction" was first coined by Maldonado et al in 1970, who described five patients with recurrent unexplained episodes of intestinal obstruction, diarrhoea, and weight loss, which sometimes progressed to death from starvation. ${ }^{2}$

The clinical syndrome of chronic intestinal pseudo-obstruction most commonly occurs secondary to diseases such as progressive systemic sclerosis, amyloidosis, and small cell carcinoma of the lung. ${ }^{3}$ The prognosis in these patients often depends on that of the underlying disorder. In contrast there is a group of patients with a similar pseudo-obstructive syndrome in whom there is no recognised underlying non-gastrointestinal disease. ${ }^{24}$ These patients with CIIP are all thought to have an abnormality of either enteric smooth muscle (visceral myopathy) ${ }^{5-7}$ or the intrinsic enteric nervous system (visceral neuropathy). ${ }^{389}$ In some patients the gut appears histologically normal or the changes are "indeterminate". ${ }^{10}$ Some patients with a primary visceral myopathy have involvement of other visceral smooth muscle, particularly the urinary tract and gall bladder. ${ }^{112}$

The literature about primary CIIP consists mainly of case reports of different clinical syndromes and underlying pathologies, involving individuals ${ }^{43}$ or families with visceral myopathy, ${ }^{74-28}$ and less commonly, visceral neuropathy. ${ }^{99-32}$ Although data about the spectrum of this condition in children have been reported, ${ }^{33}{ }^{34}$ a perspective about the clinical spectrum of disease in adults is lacking. Two groups have reported on some of these aspects of CIIP in adults. Stanghellini et al studied 42 patients, in whom intestinal pathology was available in 15 only. ${ }^{35}$ Fifty seven per cent had abnormal radiology. Many of their patients were diagnosed as having CIIP on the basis of symptoms and manometry alone. Schuffler et al studied 27 patients with chronic
Accepted for publication 10 June 1997 
intestinal pseudo-obstruction, of whom only 11 had CIIP. ${ }^{36}$

To our knowledge there is no information about the relative incidence or severity of the different primary disorders that make up this condition. The incidence of different presenting symptoms, surgical intervention, need for nutritional support, extraintestinal associations, and prognosis in adult patients have not been defined. In this study we have reviewed the clinical and pathological data on all patients managed in one tertiary referral hospital at one time to determine these aspects of the condition.

\section{Methods}

This was a cross sectional study designed to include all patients who had the clinical and radiological features of intestinal obstructionthat is, gut dilatation on radiological studies, who were managed at St Mark's Hospital between 1993 and 1995. A mechanical cause or systemic disease known to cause gut dysfunction had to have been excluded.

The case notes were reviewed to determine data about the patients' clinical characteristics, including age at onset of symptoms, time from symptom onset to diagnosis, symptoms at presentation, the presence of extraintestinal manifestations, family history, and nutritional requirements. The range of underlying pathologies, and diagnostic and therapeutic surgical interventions were also reviewed.

\section{Results}

Twenty patients fulfilled the diagnostic criteria for inclusion. There were 11 male and nine female patients with a median age of 43 years (range 22-67 years). All had radiological dilatation of the small intestine, usually involving at least the duodenal loop. Some also had large bowel dilatation.

Nineteen patients had undergone a surgical procedure to exclude a mechanical obstructing cause, to obtain tissue for histological confirmation, or as a therapeutic intervention, and in these patients histological confirmation of the diagnosis was available. In the remaining patient in whom there was no histology the diagnosis was made on the basis of typical clinical features, the presence of gut dilatation, and the clinical course, supported by manometric studies.

\section{CLINICAL PRESENTATION}

Table 1 shows clinical and pathological details. The median age of onset of symptoms was 17 years (range two weeks to 59 years) (fig 1). Patients tended to have symptom onset either in the first two decades of life, or after the age of 40 .

Figure 2 shows the proportion of patients with the main symptoms of pain $(80 \%)$, vomiting $(75 \%)$, constipation $(40 \%)$, and diarrhoea $(20 \%)$ at presentation. Other common symptoms included abdominal distension, nausea, and weight loss. One patient with megaureters also had recurrent urinary tract infections.

Most patients were not correctly diagnosed at first presentation, and sometimes for a prolonged period, at the referring hospital. Table 2 shows the presumed initial diagnoses, prior to the correct diagnoses being made. Eighty per cent of patients presented initially with suspected organic obstruction or refractory constipation.

TABLE 1 Patients' clinical characteristics

\begin{tabular}{|c|c|c|c|c|c|c|c|}
\hline Patient/sex lage & $\begin{array}{l}\text { Age at } \\
\text { symptom onset } \\
(y)\end{array}$ & $\begin{array}{l}\text { Age at first } \\
\text { operation }(y)\end{array}$ & Family history & Main symptoms & Non-GI involved & Nutritional status & Pathology \\
\hline 1. RA F/26 & $<10$ & 19 & Nil & $\mathrm{C}, \mathrm{P}$ & Nil & PEG feed & Neuropathy \\
\hline 2. $\mathrm{PA} \mathrm{F} / 54$ & $<10$ & 45 & Nil & $\mathrm{C}, \mathrm{P}, \mathrm{V}$ & Hypothyroid & Normal & Myopathy" \\
\hline 3. MB F/54 & 43 & 43 & $\mathrm{Nil}$ & $\mathrm{P}, \mathrm{V}$ & MVR/AVR & IVN & Neuropathy \\
\hline 4. PB M/died & 47 & 47 & Nil & $\mathrm{P}, \mathrm{V}$ & $\mathrm{CAH}$, vitiligo, left sided caecum & Deceased & Myopathy \\
\hline 5. MC M/died & 59 & 61 & Nil & $\mathrm{P}, \mathrm{D}, \mathrm{V}$ & Thrombosis & Deceased & Indeterminate \\
\hline 6. LF M/67 & 52 & 52 & Yes $^{\mathrm{b}}$ & P,C,V, UTI's & Hydroureters & Normal & Myopathy \\
\hline 7. NG M/30 & 18 months & 13 & Nil & $\mathrm{P}, \mathrm{C}, \mathrm{V}$ & Pancreatitis & IVN & Myopathy \\
\hline 8. $\mathrm{BH} \mathrm{F} / 37$ & 11 & 27 & Nil & $\mathrm{P}, \mathrm{V}$ & Nil & Normal & Indeterminate ${ }^{c}$ \\
\hline 9. $\mathrm{KH} \mathrm{F} / 22$ & 17 & 19 & Dystrophy & $\mathrm{C}, \mathrm{V}$ & Bladder, angio-oedema & Normal & Myopathy \\
\hline 10. WH M/66 & 35 & 35 & Nil & $\mathrm{P}$ & Nil & Normal & Neuropathy \\
\hline 11. CJ M/24 & 2 weeks & 2 & Nil & $\mathrm{v}$ & $\begin{array}{l}\text { Bladder and ureteric distension, undesc. } \\
\text { testes, retrograde ejaculation }\end{array}$ & IVN & Myopathy \\
\hline 12. PM M/49 & 7 & 10 & Nil & $\mathrm{P}, \mathrm{C}, \mathrm{V}$ & Nil & Normal & Indeterminate \\
\hline 13. JM M/28 & 13 & 19 & Nil & $\mathrm{P}, \mathrm{N}$ & Atonic bladder, hydronephrosis & IVN & Myopathy \\
\hline 14. SS F/39 & 15 & 16 & Yes $^{\mathrm{d}}$ & $\mathrm{P}$ & Nil & IVN & Myopathy \\
\hline 15. AS $\mathrm{F} / 46$ & 21 & No operation & Nil & $\mathrm{C}, \mathrm{V}, \mathrm{P}$ & Achalasia & IVN & Neuropathye \\
\hline 16. BT F/34 & 15 & 21 & Nil & $\mathrm{C}, \mathrm{V}, \mathrm{P}$ & Nil & Jejunostomy & Myopathy \\
\hline 17. HW M/62 & 40 & 58 & Nil & $\mathrm{P}$ & $\begin{array}{l}\text { Barrett's oesophagus, thrombocytopenia/ } \\
\text { leucopenia }\end{array}$ & Normal & Myopathy \\
\hline 18. $\mathrm{CW} \mathrm{F} / 33$ & 18 & 21 & Nil & $\mathrm{P}, \mathrm{D}, \mathrm{V}$ & Nil & IVN & Myopathy \\
\hline 19. PA M/58 & 57 & 57 & Nil & $\mathrm{V}, \mathrm{D}$ & Deranged LFTs ${ }^{f}$ & IVN & Myopathy \\
\hline 20. MD M/56 & 54 & 55 & Nil & $\mathrm{V}, \mathrm{D}$ & $\mathrm{CCF}, \mathrm{CRF}$, hypertension & Normal & Myopathy \\
\hline
\end{tabular}

C, constipation; $\mathrm{P}$, pain; V, vomiting; N, nausea; D, diarrhoea; IVN, intravenous nutrition; UTI, urinary tract infection; MVR, mitral valve replacement; AVR, aortic valve replacement; $\mathrm{CAH}$, chronic active hepatitis; PEG, percutaneous endoscopic gastrostomy; LFTs, liver function tests; CCF, congestive cardiac failure; CRF, chronic renal failure.

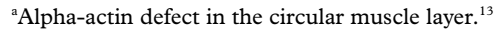

${ }^{b}$ Family history: one child has megaduodenum and symptoms of gastro-oesophageal reflux, a second child has bilateral megaureters, and a third has unilateral megaureter. ${ }^{37}$

${ }^{c}$ No histology available.

${ }^{\mathrm{d}}$ Family history: probable autosomal dominant inheritance. ${ }^{27}$

${ }^{\mathrm{e}}$ No histology available: based on gut dilatation and small bowel manometry.

fLiver biopsy shows non-specific reactive changes. 


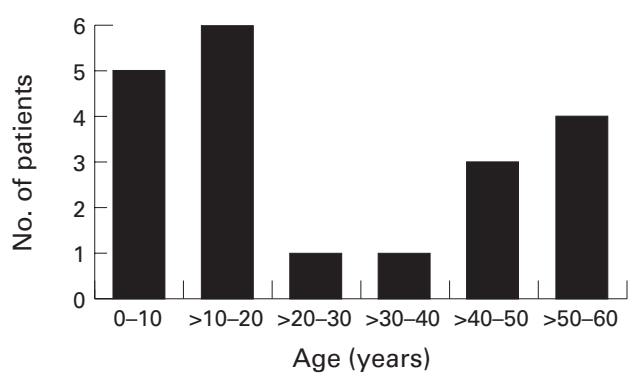

Figure 1: Spectrum of age of onset of symptoms.

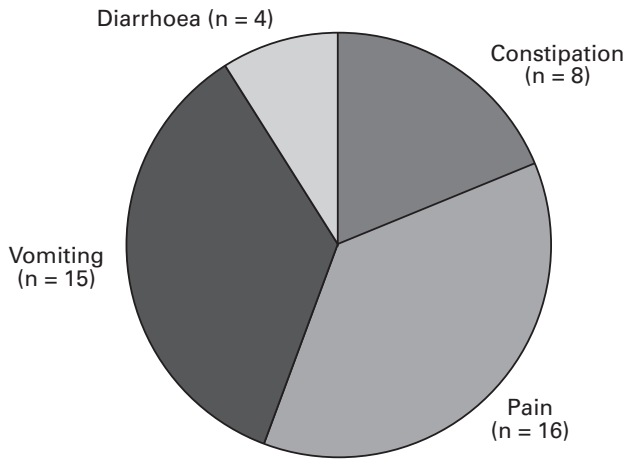

Figure 2: $\quad$ Major symptoms at presentation.

TABLE 2 Diagnoses prior to identification of correct diagnosis

\begin{tabular}{ll}
\hline Initial diagnosis & $\begin{array}{l}\text { Number (\%) } \\
\text { of patients }\end{array}$ \\
\hline $\begin{array}{l}\text { Mechanical bowel obstruction } \\
\text { Constipation }\end{array}$ & $9(45)$ \\
$\begin{array}{l}\text { Idiopathic megarectum or megacolon and } \\
\quad \text { constipation }\end{array}$ & $4(20)$ \\
$\begin{array}{l}\text { Sigmoid volvulus } \\
\text { Pseudo-obstruction }\end{array}$ & $3(15)$ \\
$\begin{array}{l}\text { Vesico-ureteric distension and acute renal } \\
\text { failure }\end{array}$ & $1(5)$ \\
Abdominal migraine/periodic syndrome & $1(5)$ \\
\hline
\end{tabular}

FAMILY HISTORY

Two patients had a family history of the same condition. Both of these patients had an autosomal dominant inherited visceral myopathy and both have been reported previously. ${ }^{27} 37$ Three of the five children of patient 6 had symptoms and radiological features of CIIP; one had megaduodenum and gastrooesophageal reflux, one had bilateral hydronephrosis and megaureters, and one had unilateral megaureter. ${ }^{37}$ Patient 14 also came from a family with visceral myopathy characterised by fibrosis and degeneration of the longitudinal muscle of the muscularis propria. She had at least six affected relatives. ${ }^{27}$ Patient 9 had a brother who died with muscular dystrophy, a previously described association of CIIP. ${ }^{33} 38$

SURGERY

Of the 19 patients who required surgical intervention for abdominal symptoms, the mean time from symptom onset to the first operation was 5.8 years. Five patients had their first operation at their first presentation as an emergency. For most patients the diagnosis was not made prior to, or at the time of, the first operation. One patient had had constipation for 30 years prior to the initial laparotomy. Figure 3 shows the age at first operation. Patient 15 had only had surgery for oesophageal symptoms for an achalasia-like syndrome with dysphagia and a dilated oesophagus. She had not had intestinal surgery and was therefore not included in fig 3 .

Table 3 shows all the surgical procedures performed in the 20 patients. A total of 59 operations were performed, encompassing 21 different types of operation. The most common operation was an exploratory laparotomy. In terms of definitive therapeutic procedures, nine patients $(45 \%)$ have either had an end ileostomy or end jejunostomy after large or small bowel resection, or both, and one patient has had an end colostomy. Nine patients have had some form of bypass procedure for vomiting refractory to medical therapy: gastroenterostomy in five and duodenojejunostomy in four. One patient has had a percutaneous gastrostomy to allow decompression and relieve vomiting.

Twelve patients had had more than three laparotomies and only two had a definitive diagnostic procedure at the first operation, such as a full thickness intestinal biopsy, thereby avoiding multiple further surgical interventions.

\section{PATHOLOGY}

Thirteen $(65 \%)$ patients had a diagnosis of visceral myopathy, two of whom came from a

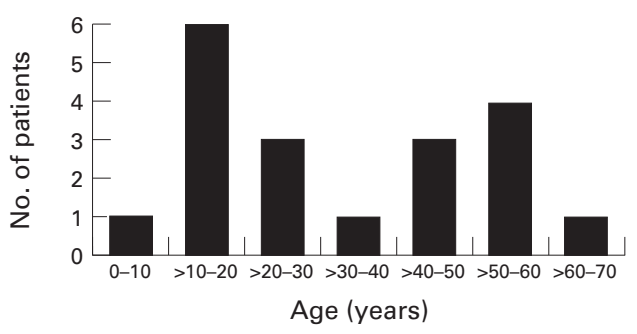

Figure 3: Spectrum of age at first operation.

TABLE 3 Surgical proceedures

\begin{tabular}{ll}
\hline Operation & $\begin{array}{l}\text { Number of } \\
\text { patients }\end{array}$ \\
\hline $\begin{array}{l}\text { Formation of end-ileostomy or } \\
\quad \text { end-jejunostomy }\end{array}$ & 9 \\
Gastroenterostomy & 5 \\
Duodenojejunostomy (including 1 resection & \\
$\quad$ of Roux-en-Y anastomosis) & 4 \\
Small bowel resection & 6 \\
Colectomy & 7 \\
Exploratory laparotomy & 4 \\
Division of adhesions & 3 \\
Ileocaecal anastomosis (after reversal of & \\
$\quad$ ileostomy) & 1 \\
Insertion of gastrostomy tube (1 for a & 2 \\
$\quad$ decompression outlet) & 2 \\
Repair of volvulus (1 gastric, 1 small bowel) & 2 \\
Duodenoplasty & 1 \\
Colostomy & 1 \\
Faecal disimpaction & 1 \\
Orchidopexy & 1 \\
Heller's myotomy followed by Nissen & 1 (plus at least \\
$\quad$ fundoplication & 4 dilatations) \\
Cystoplasty & 2 \\
Cholecystectomy & 2 \\
Vagotomy & 3 \\
Full thickness rectal biopsy & 1 \\
Full thickness small bowel biopsy & 1 \\
Ureterostomies & 1 \\
Repair of ruptured stomach & 1 \\
\hline
\end{tabular}


family of affected patients. Patient 9 had probable pathological features of myopathy with the circular layer of the muscularis propria showing an unusual degree of splitting of muscle bundles by interstitial connective tissue supported by characteristic myopathic features on her transit studies and an associated adynamic bladder; this was the patient with a family history of muscular dystrophy.

Patients with visceral myopathy most commonly had a degenerative condition with atrophy and fibrosis of one or both layers of the muscularis propria, associated with vacuolar degeneration and a degree of secondary subvillous atrophy. There was a variable amount of inflammatory infiltrate in some specimens. Inflammatory myopathy was less common. One patient (patient 4) had a very dense inflammatory myositis and died after a short severe illness.

Four patients $(20 \%)$ had a visceral neuropathy, all of whom were sporadic cases. Three had histological confirmation. Patient 1 had an inflammatory plexitis, and studies using the polymerase chain reaction to detect herpes virus DNA have shown the presence of Ebstein-Barr virus in her small bowel as a possible aetiological agent. ${ }^{39}$ Patient 3 had degenerative neurones in the myenteric plexus but also had some fibrosis and patchy degenerative changes in the muscularis propria; these muscle changes were interpreted as being secondary to the more prominent neural abnormality as described in $1985 .^{40}$ Patient 10 had gross changes of nerve cell loss and degeneration, with neuronal swelling, vacuolation, and clubbing in the myenteric plexus on silver staining. The fourth patient (patient 15), the only patient who had not had an abdominal operation, presented with an achalasia-like syndrome and subsequently had a typical intestinal obstructive-like syndrome, described by Schuffler and Pope in $1976 .{ }^{41}$ Small intestinal motility studies in this patient had shown neuropathic type changes with disorganised motor activity.

Four patients had normal routine haematoxylin and eosin histology, despite having a dilated non-obstructed gut, and characteristic clinical features. One of these four patients (patient 2) had absent circular muscle layer staining for the contractile protein $\alpha$ actin on immunohistochemical staining, ${ }^{13}$ and has been included in the patients having a visceral myopathy.

\section{EXTRAINTESTINAL ABNORMALITIES}

The most common non-intestinal manifestation in these patients was genitourinary involvement (see table 4 ).

CLINICAL COURSE

At the time of undertaking this study $18 / 20$ patients were alive and had had a chronic course.

\section{Mortality}

Two patients died after a short severe illness, both of whom required parenteral nutrition. Patient 5 died two years after the onset of
TABLE 4 Extraintestinal associations

\begin{tabular}{ll}
\hline Extraintestinal association & $\begin{array}{l}\text { Number of } \\
\text { patients }\end{array}$ \\
\hline Hydronephrosis/hydroureter & 3 \\
Megacystis & 3 \\
Chronic hepatitis & 2 \\
Cardiomyopathy & 2 \\
Skin abnormalities: vitiligo, angio-oedema & 2 \\
Haematological: thrombocytopenia & 2 \\
Oesophageal: Barrett's, achalasia & 2 \\
Pancreatitis & 1 \\
Hypothyroidism & 1 \\
Cryptorchidism/retrograde ejaculation & 1 \\
Faecal incontinence & 1 \\
Chronic renal failure/hypertension & 1
\end{tabular}

symptoms; he had extensive thrombosis involving the inferior and superior vena cavae, and died following a myocardial infarction. Despite having a grossly dilated gut throughout his illness, the histology was normal. Post mortem examination failed to show any further gut abnormality, or extraintestinal cause for his illness.

Patient 4 had a florid myositis and died within two years of the onset of symptoms with a bronchopneumonia. To our knowledge there is only one other report of a patient dying with florid myositis-this involved a child with disease from the age of six months. ${ }^{42}$ Our patient had a dense chronic inflammatory infiltrate within the muscle of the muscularis propria, mainly composed of lymphocytes and plasma cells, in association with almost complete replacement of the longitudinal muscle by fibrosis. The inflammatory infiltrate affected the full thickness of the bowel wall, sparing the myenteric and submucosal plexuses. He had an associated chronic active hepatitis, diagnosed histologically because of the presence of abnormal liver function tests associated with hepatomegaly. The only other major report of myositis in adults consisted of four patients with a polyclonal lymphoid infiltrate occurring in the muscularis propria, mucosa, and submucosa. ${ }^{43}$

Nutrition

Of the remaining 18 patients, only eight were nutritionally independent without the need for supplemental intravenous or enteral fluids or calories. Two patients had enteral feeding regimens. Patient 1 had received previous feeding via a percutaneous gastrostomy, but had managed to cope subsequently with oral nutritional supplements only. Patient 16 had a feeding jejunostomy tube. Eight patients were dependent on parenteral nutritional support and represented $16 \%$ of all the patients on home intravenous nutrition at our hospital.

\section{Drug treatment}

Five of the 18 CIIP patients who were still alive were opiate dependent because of chronic abdominal pain. Eleven patients required regular antibiotics for bacterial overgrowth, either on a rotating basis with two or three different antibiotics, or on an "as required" basis. Most of these patients have had documented bacterial overgrowth on hydrogen breath testing. 
All patients have had several trials of promotility agents such as cisapride, erythromycin, metoclopramide, and domperidone. Patient 6 , with a familial visceral myopathy, had a dramatic and sustained response to erythromycin, with cessation of vomiting and weight gain of 3 stone. No other patient had benefited substantially from a prokinetic drug. Some patients took antidiarrhoeal medications, either for a high output stoma or for diarrhoea. A minority of patients had been tried on intravenous neostigmine ${ }^{2445}$ for acute pseudoobstructive symptoms, with only mild benefit and considerable side effects of cramping and sweating. Other drugs which had been tried in many patients without benefit included octreotide, tricyclic antidepressants (for their effect on visceral pain), antispasmodics such as hyoscine butylbromide (Buscopan), and atenolol to oppose $\beta_{1}$ sympathetic inhibition. ${ }^{46}$

Patients with previous ileal resection received regular vitamin $B_{12}$ injections, and patient 14 required supplementation with fat soluble vitamins due to documented vitamin $\mathrm{D}$ and $\mathrm{E}$ deficiencies.

Five patients have required the support of either a psychiatrist or psychologist, because of the difficulty in coping with chronic illness or depression. Three patients were opiate dependent.

\section{Discussion}

This cross sectional study has characterised the spectrum of clinical, pathological, and prognostic features of the syndrome of CIIP in adults attending a tertiary referral hospital. It was designed to give an overview of the condition which case reports cannot do, because of their focus on individual patients and their inherent bias in reporting unusual features. It demonstrates that in a specialised centre, using our diagnostic criteria, most patients have a visceral myopathy, with a prolonged but disabling course.

The condition of CIIP is rare. We do not believe that our patients are completely typical of affected patients in the community. However only a limited number of tertiary referral centres are likely to manage enough patients with this condition to enable a report such as this to be composed. Some patients will have a relatively benign course with limited symptoms and no need for nutritional supplementation, as occurred in some of the relatives of patient 14. Although this family presumably shared the same intestinal pathology, some family members were able to live without substantial medical intervention. These patients will be underrepresented in a series such as this.

Further discussion is warranted regarding the inclusion criteria for a study of this type, which is aiming to define a clinical spectrum. We chose to include only patients with a certain diagnosis of intestinal pseudo-obstruction, and therefore did not include patients who had pain in the absence of a dilated gut. Others have included such patients in their reports ${ }^{35}$ and they may indeed represent an early or different form of the disease. In the series from the Mayo clinic there were 15 patients in whom histology was available, none of which showed smooth muscle changes. This group of patients may reflect a different spectrum of CIIP; it may be that patients with visceral myopathy are more likely to present with a dilated gut. Abdominal pain is common, and we felt more confident if the objective criterion of a dilated gut was adhered to. The need for a radiological abnormality in defining such patients has been previously expressed. ${ }^{47}$ Furthermore, in 19 of our 20 patients tissue was available for examination, and was abnormal in the majority. We believe that a dilated gut is an indisputable abnormality. We also believe that histological assessment remains a gold standard for diagnosis, although its interpretation is sometimes subjective or indeterminate, and occasionally the appearance is normal. Advances in the use of special techniques such as contractile protein immunohistochemistry are likely to decrease the number of patients with "normal" histology in the future.

Apart from patient 15 with a radiologically dilated gut in whom disorganised small intestinal motility suggested neuropathic pseudoobstruction, we did not use small intestinal manometry as a criterion for inclusion in this study. We, and others feel that these measurements are not yet specific and sensitive enough to serve as precise markers of disease. ${ }^{47}$

Most patients have obstructive symptoms for many years prior to a laparotomy. Recognition of the true underlying abnormality was often delayed. Schuffler et al have reported that apart from organic bowel obstruction, the most common misdiagnosis in their experience was obstruction of the duodenum by the superior mesenteric artery. ${ }^{36}$ Other diagnoses included achalasia, diverticulosis, psychogenic vomiting, functional bowel disease, megacolon, colitis, megaduodenum, malabsorption syndrome, and adhesions. Pain and vomiting were the most common symptoms, similar to previous reports by Schuffler $e t a l{ }^{36}$ who had 11 patients with primary CIIP in their review of 27 patients, and Stanghellini et al, who studied 42 patients with manometrically defined CIIP. ${ }^{35}$

The extraintestinal associations of primary CIIP have been well documented. The most common association is genitourinary smooth muscle involvement in patients with hereditary visceral myopathy. We noted a wide range of associated abnormalities; which of these occurred by chance remains to be determined as more patients are reported in the literature.

In the review by Schuffler et al four of the eleven patients with primary pseudoobstruction died at a mean age of 57 years. ${ }^{36}$ Some of these deaths were from apparently unrelated causes. Two of our patients (10\%) died within two years of the onset of symptoms. The relatively low death rate observed in recent years, compared with early reports, relates mainly to improvement in available nutritional support.

The literature suggests a relatively poor response to pharmacological treatment for the primary motility disorder. ${ }^{14}{ }^{48-51}$ Camilleri et al studied the value of cisapride in treating symptoms in 15 patients with CIIP. ${ }^{52}$ Despite 
improvement in physiological parameters there was no corresponding improvement in symptoms. Verne et al showed a beneficial effect on small intestinal motility in four of five patients with pseudo-obstruction secondary to progressive systemic sclerosis, but a poor response in patients with CIIP. ${ }^{51}$ These authors combined the use of erythromycin with octreotide, having shown no benefit from erythromycin alone. Only one of our patients responded to pharmacological therapy, but the response was so marked that we feel a trial of different drug treatments may be warranted in most patients. The syndrome of primary CIIP is so heterogeneous that there is likely to be a wide range of responses to different treatments. There is a role for other non-specific pharmacological therapy, such as antibiotics for bacterial overgrowth and loperamide for diarrhoea.

The role of surgical treatment in these disorders remains poorly defined. Patients vary in their clinical expression and problems, despite even identical histology. Surgical treatment therefore needs to be tailored to the individual symptoms and objective evidence of regional disturbances in transit, such as might be observed with radioisotope studies. ${ }^{53}$ Surgery in the form of bypass, limited resection, or decompressing venting stomas has had varying success in our patients and in the literature..$^{54-56}$

Two patients, both with visceral myopathy, had a family history of affected relatives. There have been about 15 such families reported in the literature. Visceral neuropathies are more commonly sporadic although there have been reports of familial cases. ${ }^{30-32}$

Most patients with visceral myopathy have light microscopic changes of smooth muscle fibrosis and vacuolar and other degenerative changes in the circular and longitudinal layers of the intestinal wall, although the changes often involve only one muscle layer. ${ }^{57}$ Patient 2 in our series, who has been reported previously, was the first case of a specific protein defect reported with no underlying structural abnormality demonstrable by either light or electron microscopy. ${ }^{13}$ Future routine use of special techniques such as electron microscopy, immunohistochemical staining for specific contractile elements, and more refined staining for neurological elements will decrease the number of patients in whom histological examination is apparently "normal". Patients having a laparotomy for apparent obstruction who are found to lack a mechanical cause should have tissue processed to allow special examinations. Such processing includes the storage of tissue in liquid nitrogen for specific immunohistochemical staining, and glutaraldehyde for electron microscopy.

The syndrome of primary CIIP in adults overlaps with, but is not identical to, the syndrome seen in infants and children. Many infants and children die with what is probably a congenital abnormality. ${ }^{33} 34$ A subgroup of children with less severe disease goes on to form part of the adult population; five of our patients had the onset of symptoms before the age of 10 years.
In summary, primary CIIP is a heterogeneous disorder. The major aims in management should be early diagnosis, avoidance of unnecessary repeated laparotomies, maintaining nutrition, symptom control, attempts at restoring motility, and the commitment to long term care.

1 Dudley HA, Sinclair IS, McLaren IF, McNair TJ, Newsam JE. Intestinal pseudo-obstruction. F R Coll Surg Edinb 1958; 3: $206-17$.

2 Maldonado JE, Gregg JA, Green PA, Brown AL Jr. Chronic idiopathic intestinal pseudo-obstruction. Am F Med 1970; 49: $203-12$.

3 Krishnamurthy S, Schuffler MD. Pathology of neuromuscular disorders of the small intestine and colon. Gastroenterology 1987; 93: 610-39.

4 Anuras S, Crane SA, Faulk DL, Hubel KA. Intestinal pseudoobstruction [clinical conference]. Gastroenterology 1978; 74: 1318-24.

5 Schuffler MD. Chronic intestinal pseudo-obstruction syndromes. Med Clin North Am 1981; 65: 1331-58.

6 Schuffler MD, Lowe MC, Bill AH. Studies of idiopathic intestinal pseudoobstruction. I. Hereditary hollow visceral myopathy: clinical and pathological studies. Gastroenterology 1977; 73: 327-38.

7 Schuffler MD, Pope CE. Studies of idiopathic intestinal pseudoobstruction. II. Hereditary hollow visceral myopathy: family studies. Gastroenterology 1977; 73: 339-44.

8 Schuffler MD, Leon SH, Krishnamurthy S. Intestinal pseudoobstruction caused by a new form of visceral neuropathy: palliation by radical small bowel resection. Gastroenterology 1985; 89: 1152-6.

9 Schuffler MD, Bird TD, Sumi SM, Cook A. A familial neuronal disease presenting as intestinal pseudo-obstruction. Gastroenterology 1978; 75: 889-98.

$10 \mathrm{Kamm}$ MA. Chronic intestinal pseudo-obstruction in adults. In: Kamm MA, Lennard-Jones JE, eds. Constipation. Petersfield, UK: Wrightson Biomedical Publishing, 1994; 241-51.

11 Bonsib SM, Fallon B, Mitros FA, Anuras S. Urological manifestations of patients with visceral myopathy. $\mathcal{F}$ Urol 1984; 132: 1112-6.

12 Christensen J, Dent J, Malagelada JR, Wingate DL. Pseudoobstruction. Gastroenterology International 1990; 3: 107-19.

13 Smith VV, Lake BD, Kamm MA, Nicholls RJ. Intestinal pseudo-obstruction with deficient smooth muscle alphapseudo-obstruction with deficient smo
actin. Histopathology 1992; 21: 535-42.

14 Lewis TD, Daniel EE, Sarna SK, Waterfall WE, Marzio L. Idiopathic intestinal pseudoobstruction. Report of a case, with intraluminal studies of mechanical and electrical activity, and response to drugs. Gastroenterology 1978; 74: $107-11$

15 Law DH, Eyck EAT. Familial megaduodenum and megacystis. Am J Med 1962; 33: 911-22.

16 Anuras S, Mitros FA, Nowak TV, Ionasescu VV, Gurll NJ, Christensen $\mathrm{J}$, et al. A familial visceral myopathy with external ophthalmoplegia and autosomal recessive transmission. Gastroenterology 1983; 84: 346-53.

17 Faulk DL, Anuras S, Gardner GD, Mitros FA, Summers RW, Christensen J. A familial visceral myopathy. Ann Intern Med 1978; 89: 600-6.

18 Jones SC, Dixon MF, Lintott DJ, Axon AT. Familial visceral myopathy. A family with involvement of four generations. myopathy. A family with involy
Dig Dis Sci 1992; 37: 464-9.

19 Fitzgibbons PL, Chandrasoma PT. Familial visceral myopathy. Evidence of diffuse involvement of smooth muscle. Am I Surg Pathol 1987; 11: 846-54

20 Newton WT. Radical entrectomy for hereditary megaduodenum. Arch Surg 1968; 96: 549-53.

21 Faulk DL, Anuras S, Christensen J. Chronic intestinal pseudoobstruction. Gastroenterology 1978; 74: 922-31.

22 Shaw A, Shaffer H, Teja K, Kelly T, Grogan E, Bruni C. A perspective for pediatric surgeons: chronic idiopatic intestinal pseudoobstruction. F Pediatr Surg 1979; 14: 71927.

23 Jacobs E, Ardichvili D, Perissino A, Gottignies P, Hanssens J-F. A case of familial visceral myopathy with atrophy and fibrosis of the longitudinal layer of the entire small bowel. fibrosis of the longitudinal layer of

24 Ionasescu VV, Thompson HS, Aschenbrener C, Anuras S, Risk WS. Late onset oculogastrointestinal muscular Risk WS. Late onset oculogastrointestina
dystrophy. Am f Med Genet 1984; 18: 781-8.

25 Alstead EM, Murphy MN, Flanagan AM, Bishop AE, Hodgson HJF. Familial autonomic visceral myopathy with degeneration of muscularis mucosae. F Clin Pathol 1988; 41: 424-9.

26 Ionasescu VV. Oculogastrointestinal muscular dystrophy. Am f Med Genet 1983; 15: 103-12.

27 Rodrigues CA, Shepherd NA, Lennard-Jones JE, Hawley PR, Thompson HH. Familial visceral myopathy: a family with at least six involved members. Gut 1989; 30: 1285-92.

8 Anuras S, Mitros FA, Milano A, Kuminsky R, Decanio R, Green JB. A familial visceral myopathy with, Decanio R, Green JB. A familial visceral myopathy with dilatation of 385-90.

29 Faber J, Fich A, Steinberg A, Steiner I, Granot E, Alon I, et al. Familial intestinal pseudoobstruction dominated by a 
progressive neurologic disease at a young age. Gastroenterology 1987; 92: 786-90

30 Roy AD, Bharucha $\mathrm{H}$, Nevin NC, Odling-Smee GW. Idiopathic intestinal pseudo-obstruction: a familial visceral neuropathy. Clin Genet 1980; 18: 291-7.

31 Mayer EA, Schuffler MD, Rotter JI, Hanna P, Mogard M Familial visceral neuropathy with autosomal dominan transmission. Gastroenterology 1986; 91: 1528-35.

32 Camilleri M, Carbone LD, Schuffler MD. Familial enteric neuropathy with pseudoobstruction. Dig Dis Sci 1991; 36: 1168-71.

33 Krishnamurthy S, Heng Y, Schuffler MD. Chronic intestinal pseudo-obstruction in infants and children caused by diverse abnormalities of the myenteric plexus. Gastroenterology 1993; 104: 1398-408.

34 Navarro J, Sonsino E, Boige N, Nabarra B, Ferkadji L, Mashako LMN, et al. Visceral neuropathies responsible for chronic intestinal pseudo-obstruction syndrome in pediatric practice: analysis of 26 cases. F Pediatr Gastroenterol Nutr 1990; 11: 179-95.

35 Stanghellini V, Camilleri M, Malagelada JR. Chronic idiopathic intestinal obstruction: clinical and intestinal manometric findings. Gut 1987; 28: 5-12.

36 Schuffler MD, Rohrmann CA, Chaffee RG, Brand DL Delaney $\mathrm{JH}$, Young JH. Chronic intestinal pseudoobstruction. A report of 27 cases and review of the literature. Medicine Baltimore 1981; 60: 173-96.

37 Higman D, Peters P, Stewart M. Familial hollow visceral myopathy with varying urological manifestations. $\mathrm{Br} \mathcal{F}$ Uro 1992; 70: 435-8.

38 Leon SH, Schuffler MD, Kettler M Rohrmann CA. Chronic intestinal pseudoobstruction as a complication of Duchenne's muscular dystrophy. Gastroenterology 1986; 90 455-9.

39 Debinski HS, Kamm MA, Talbot IC, Khan G, Kangro HO, Jeffries DI. DNA viruses in the pathogenesis of sporadic chronic idiopathic intestinal pseudo-obstruction. Gut 1997; 41: 100-6.

40 Smout AJ, De Wilde K, Kooyman CD, Ten-Thije OJ. Chronic idiopathic intestinal pseudoobstruction. CoexistChronic idiopathic intestinal pseudoobstruction. CoexistSci $1985 ; 30: 282-7$.

41 Schuffler MD, Pope CE. Esophageal motor dysfunction in idiopathic intestinal pseudoobstruction. Gastroenterology 1976; 70: 677-82

42 Nezelof C, Vivien E, Bigel P, Nihoul-Fekete C, ArnaudBattandier F, Bresson JL, et al. Idiopathic myositis of the small intestine. An unusual cause of chronic intestinal pseudo-obstruction in children. Arch Fr Pediatr 1985; 42 $823-8$
43 McDonald GB, Schuffler MD, Kadin ME, Tytgat GN. Intestinal pseudoobstruction caused by diffuse lymphoid infiltration of the small intestine. Gastroenterology 1985; 89: 882-9.

44 Sullivan MA, Snape WJ Jr, Matarazzo SA, Petrokubi RJ, Jeffries G, Cohen S. Gastrointestinal myoelectric activity in idiopathic intestinal pseudo-obstruction. $N$ Engl $\mathcal{F}$ Med 1977; 297: 233-8.

45 Hutchinson R, Griffiths C. Acute colonic pseudoobstruction: a pharmacological approach. Ann R Coll Surg Engl 1992; 74: 364-7.

46 McIntyre AS, Thompson DG, Day S, Burnham WR, Walker ER. Modulation of human upper intestinal nutrient transit by a beta adrenoceptor mediated pathway. Gut 1992; 33: 1062-70.

47 Verne GN, Sninsky CA. Chronic intestinal pseudoobstruction. Dig Dis 1995; 13: 163-81.

48 Camilleri M, Brown ML, Malagelada JR. Impaired transit of chyme in chronic intestinal pseudoobstruction: correction by cisapride. Gastroenterology 1986; 91: 619-26.

49 Dyer NH, Dawson AM, Smith BF, Todd IP. Obstruction of bowel due to lesion in the myenteric plexus. BMF 1969; 1: 686-9.

50 Lipton AB, Knauer CM. Pseudo-obstruction of the bowel. Therapeutic trial of metoclopramide. Am F Dig Dis 1977; 22: $263-5$.

51 Verne GN, Eaker EY, Hardy E, Sninsky CA. Effect of octreotide and erythromycin on idiopathic and sclerodermaassociated intestinal pseudoobstruction. Dig Dis Sci 1995; 40: 1892-901

52 Camilleri M, Malagelada JR, Abell TL, Brown ML, Hench $\mathrm{V}$, Zinsmeister AR. Effect of six weeks of treatment with cisapride in gastroparesis and intestina

53 Greydanus MP, Camilleri M, Colemont LJ, Phillips SF, Brown ML, Thomforde GM. Ileocolonic transfer of solid chyme in small intestinal neuropathies and myopathies. Gastroenterology 1990; 99: 158-64.

54 Mughal MM, Irving MH. Treatment of end stage chronic intestinal pseudo-obstruction by subtotal enterectomy and intestinal pseudo-obstruction by subtotal enterect

55 Anuras S, Shirazi S, Faulk DL, Gardner GD, Christensen J. Surgical treatment in familial visceral myopathy. Ann Surg 1979; 189: 306-10.

56 Murr MM, Sarr MG, Camilleri M. The surgeon's role in the treatment of chronic intestinal pseudoobstruction. Am $\mathcal{f}$ Gastroenterol 1995; 90: 2147-51.

57 Colemant LJ, Camilleri M. Chronic intestinal pseudoobstruction: diagnosis and treatment. Mayo Clin Proc 1989; 64: $60-70$. 